\title{
FUSION OF HYPERSPECTRAL IMAGES AND LIDAR DATA FOR CIVIL ENGINEERING STRUCTURE MONITORING
}

\author{
A. Brook ${ }^{\mathrm{a}, *}$, E. Ben-Dor ${ }^{\mathrm{a}}$, R. Richter ${ }^{\mathrm{b}}$ \\ ${ }^{a}$ Remote Sensing and GIS Laboratory, Tel-Aviv University, Israel - rsl@tau.ac.il \\ ${ }^{\mathrm{b}}$ DLR Institute of Space Systems, Bremen, Germany - r.richter@dlr.de
}

Commission VI, WG VI/4

KEY WORDS: LIDAR, Hyperspectral, Fusion data, 3D maps, Urban Environment

\begin{abstract}
:
Investigation of civil engineering materials includes a wide range of applications that requires three-dimensional (3D) information. Complex structures shapes and formations within heterogeneous artificial/natural land covers under varying environmental conditions requires knowledge on the 3D status of the urban materials for better (visual) interpretation of polluted sources. Obtaining 3D information and merge them with aerial photography is not a trivial task. It is thus, strongly needed to develop new approaches for near real time analysis of the urban environment with natural 3D visualization of extensive coverage. The hyperspectral remote sensing (HRS) technology is a promising and powerful tool to assess degradation of urban materials in artificial structures by exploring possible chemical physical changes using spectral information across the VIS-NIR-SWIR spectral region (400-2500nm). This technique provides the ability for easy, rapid and accurate in situ assessment of many materials on a spatial domain within near real time condition and high temporal resolution. LIDAR technology, on the other hand, offers precise information about the geometrical properties of the surfaces within the study areas and can reflect different shapes and formations of the complex urban environment. Generating a monitoring system that is based on the integrative fusion between HRS and LIDAR data may enlarge the application envelop of each technology separately and contribute valuable information on urban runoff and planning. The aim of the presented research is to implement this direction and define set of rules for practical integration between the two datasets. A fusion process defined by integrative decision tree analysis includes spectral/spatial and 3D information is developed and presented.
\end{abstract}

\section{INTRODUCTION}

For many years, panchromatic aerial photographs have been the main source of remote sensing data for detailed inventories of urban areas. These investigations have been focusing on the development of automated methods for geometric threedimensional (3D) assessment of man-made objects, mainly buildings and roads. Due to the variety and complexity of the mapped categories, their assessment was based mostly on visual interpretation of CIR (color infrared photography) aerial photographs. The imagery interpretation is based on a basic characterisation of a given object as opposed by its visible information such as: shape (external form, outline, or configuration), size, patterns (spatial arrangement of an object into distinctive forms), shadow (indicates the outlines, length, and useful to measure the height, or slops of the terrain), tone (color or brightness of an object, smoothness of the surface etc) (1). The problem of a limited swath coverage and a twodimensional projection over urban areas have been overcame with the wider availability of airborne multispectral sensors, which recently have been complemented by high resolution (swath, pixel size and temporal) satellite-based systems (IKONOS). However, still the limits of spectral information of non-vegetated material render exact identification of many urban targets. In this regard the airborne hyperspectral Remote Sensing (HRS) technology using data from airborne sensors has opened new frontiers for surface differentiation of homogeneous material based on spectral characteristics (2). This capability enables quantitative information extraction of biochemical, geochemical and chemical parameters of the targets in question.

The spectral characteristics of the urban surfaces are known to be rather complex as it composed from many materials. Given the high degree of spatial and spectral heterogeneity of and within various artificial and natural land cover categories, the application of remote-sensing technology to mapping the urban environment requires specific attention to the both spectral and 3D dimensions.

Civil engineering discipline requires high temporal, spatial and spectral resolutions type of information, specifically to track after possible sources of pollution (3). Consequently, a new approaches for near real time analysis of the urban environment with natural three dimensional visualization of extensive coverage, is strongly needed.

Whereas the HRS technology provides quantitative information on the urban targets that adds to the regular spatial 2 dimension, the LIDAR information provides the third spatial dimension that together may sum up to a 4D set of information.

The aim of the presented research is thus to specify a set of rules for establishing a fusion system by defining an integrative decision tree include spectral/spatial and three dimensional information data bases and monitoring the fusion capability between both HRS and LIDAR systems for civil engineering and urban planning applications.

\footnotetext{
* Anna Brook, Remote Sensing and GIS Laboratory, Tel-Aviv University, Israel, +972-54-4-947-067 - anna.brook@gmail.com
} 


\section{METHODOLOGY}

\subsection{Study Area}

The AISA ES and LIDAR data used in this study were acquired over the sub-urban area of Ma'a lot Tarshiha $\left(33^{\circ} 00^{\prime} 52^{\prime \prime} \mathrm{N}\right.$ and $\left.35^{\circ} 17^{\prime} \mathrm{E}\right)$ mining district in the northern Israel on October 10 , 2006 at 11:20 GMT. This area combines natural and engineered terrains (average elevation of $560 \mathrm{~m}$ ), a hill on the north of studying polygon area and a valley in the centre. The neighbourhood associate two and three floors cottage houses with tile roofs, white coloured fibreglass flat roofs and surfaces, asphalt roads and parking lots, man planted and natural vegetation gravel paths and bare forest soils.

\subsection{Data Acquisition Systems}

AISA ES is an airborne imaging spectrometer designed and built by Specim LTD. It simultaneously acquires images in 198 contiguous spectral bands, covering the $400-2500 \mathrm{~nm}$ spectral region. It usually flies on aircraft at altitude of above $3.3 \mathrm{~km}$. A standard AISA ES data set is a three-dimensional data cube in non-earth coordinate system. It has 286 pixels in the cross-track direction, hundred of pixels in the along-track direction, and 198 spectral bands for each pixel (programmed for this specific case study).

The principles of LIDAR are a measured range from a platform with a position and attitude determined from GPS/INS using a scanning device which determines the distance from the sensor to the ground of a series of points roughly perpendicular to the direction of flight. As a result, the raw airborne LIDAR data is collected in the GPS reference system WGS 84. The wavelength in which out lasers operated was $1050 \mathrm{~nm}$. The LIDAR system was operated with $100 \mathrm{~Hz}$ configuration. Airborne laser scanner record up to 5 different returns (multiple returns), thus if a laser pulse or a part of the pulse is reflected from a roof top or the top of a tree, the sensor will record the first return. However, a spatial resolution of $0.5 \mathrm{~m}$ was suitable for sub-urban area mapping.

\subsection{Data Processing Techniques}

\subsubsection{AISA-ES Hyperspectral Data Classification}

A pre-processing stages followed by atmospheric correction of the 2006 AISA ES Ma'a lot Tarshiha, northern Israel scene was performed using a modified version of the ATCOR4 with an inflight calibration mode (4). An improved surface reflectance spectrum has been presented after removing the atmospheric absorption, scattering effects and possible remaining spikes. Those spikes and artifacts in the spectral domain would most likely depredate extracted spectral information and reduces classification accuracies. The classification technique based on unsupervised method of PPI (Pure Pixels Index) extracted as an endmembers for the scene, and SAM (Spectral Angle Mapper) as a classification tool for spectral similarity between endmembers and the rest of image pixels (5). Figure 1 presents results of PPI in spectral library of extracted endmembers.

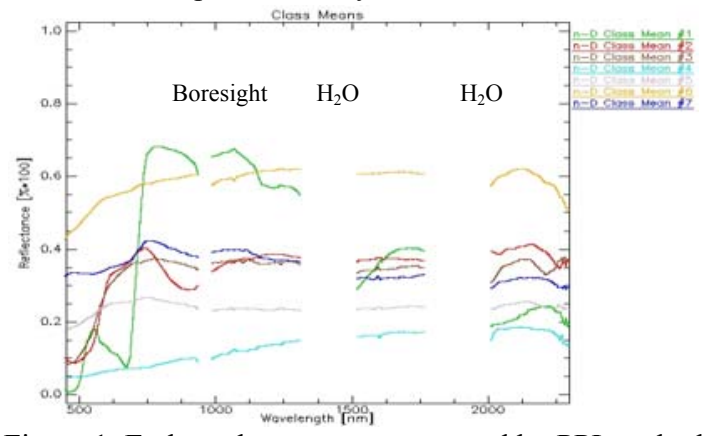

Figure 1. Endmembers spectra extracted by PPI method
Figure 2 presents a classification algorithm (6).

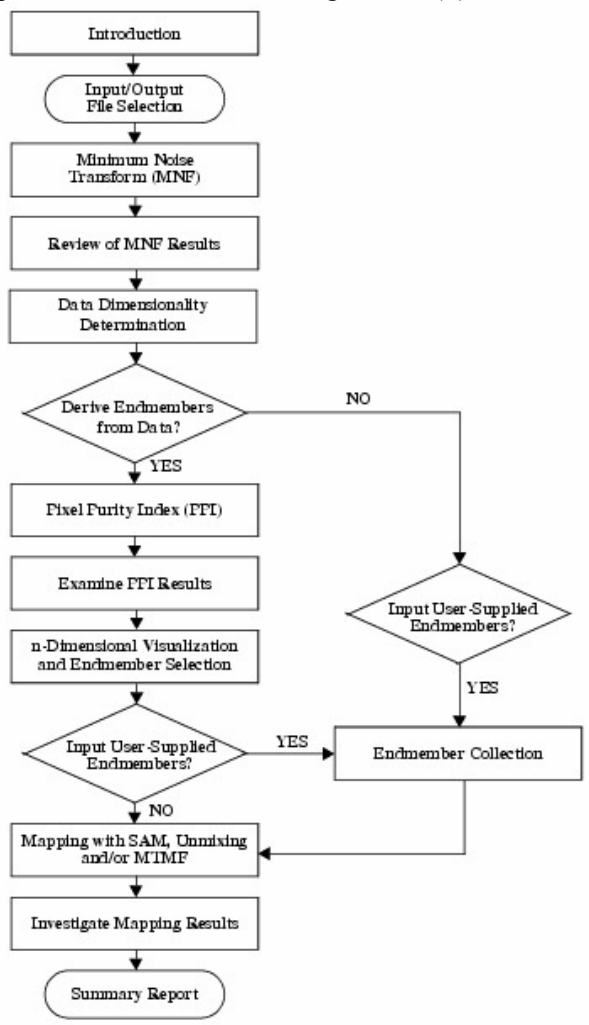

Figure 2. Spectral Hourglass Wizard Algorithm

The thematic map was estimated by Error/Confusion Matrix (7) with overall accuracy of $98.4 \%$ showing a highest matching with a study area. Kappa coefficient (8) was 0.994 and calculated with equation (1):

$$
\text { Карра }=\frac{N \sum_{i=1}^{r} x_{i i}-\sum_{i=1}^{r}\left(x_{i+} \cdot x_{+i}\right)}{N^{2}-\sum_{i=1}^{r}\left(x_{i+} \cdot x_{+i}\right)}
$$

where $\quad r=$ number of rows

$\mathrm{x}_{\mathrm{ii}}=$ number of selected class on diagonal

$\mathrm{x}_{\mathrm{i}+}=$ number of measurements within row

$\mathrm{x}_{+\mathrm{i}}=$ number of measurements within column

$\mathrm{N}=$ total number of measurements

The coefficient presents a high accuracy of classification output after its random portion has been accounted for.

\subsubsection{LIDAR Surface Analysis}

LIDAR surface analysis was first represented a raw terrain of the scanned scene. To model surface variation, we used a Kriging approach to interpolate all measurement points (9). Kriging models have their origins in mining and geostatistical applications involving spatially and temporally correlated data (10). In this paper, we utilized the Kriging Gaussian correlation function for visualizing and illustrating edited DEM by using a surface response function.

Segmentation Procedure: Minimum filters (11) are used to perform LIDAR-based DEM (Digital Elevation Model) as a DSM (Digital Surface Model). The main objective of the filtering process was to detect and consequently remove points above the ground surface in order to recognize height DSM points in the data set. The minimum filter size should be large enough to include data points that are not part of the noise. 
However, iterative approaches could be used to avoid the effect of noise. In this research, the size of the filter was $2 \times 2$. The filtering is repeated iteratively until the DSM was extracted.

The next step was buildings extraction with calculated RMS. If the difference between the DSM and the DEM for any pixel was greater than a given threshold (of $4 \mathrm{~m}$ as a one floor building), the point was treated as a building pixel. The value of the threshold was determined using previous knowledge about the area.

The roads extracted by conversion of selected lines to polylines using a rule-based system. The mechanism computed in three steps. The first step was to find all possible intersections between all borderlines. The next step was to generate all polylines from all recorded intersections. The third step was to find the optimal polylines which are regular surfaces that represents the roads contour. Those polylines were chosen using a template matching technique, which was matched across hypotheses. While the largest correlation and minimum number of vertices was selected to be the best fitting polylines.

Automated delineation of roofs planes: Rottensteiner (12) described a method for reconstruction of buildings by polyhedral models using LIDAR data. His algorithm for planar segmentation describing a new algorithm for step edge detection shows a flow for the geometric reconstruction of buildings consists of two steps: 1. Detection of roof planes based on a segmentation of the DSM to find planes which are expanded by region growing, 2. Grouping of roof planes and roof plane delineation: Coplanar roof segments are merged, and hypotheses for intersection lines and/or step edges are created based on an analysis of the neighborhood relations.

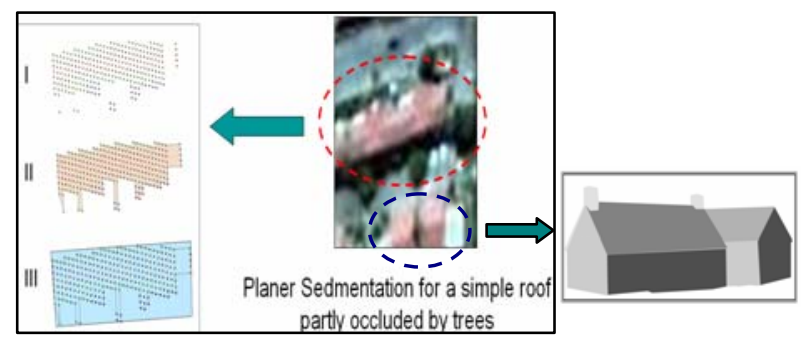

Figure 3. Automated delineation of roofs planes

The following steps took place accordingly:

I. Extracted LIDAR points

II. Connected vertexes to polygons

III. Combination of all step edges and intersection lines to form

\section{AUTOMATIC REGISTRATION BETWEEN AISA ES IMAGE AND FEATURES EXTRACTED FROM LIDAR}

Data fusion techniques combine data from multiple sensors, and related information from associated databases, to achieve improved accuracy and more specific inferences that could be achieved by the use of single sensor alone. A long term debate of HRS geo-referenced data and its pre-processing priority, encourage us to match a LIDAR DSM to a HRS raw geometry. This method would keep a spatial configuration of HRS image, thus would not change or de-format a pixel radiometry and will be relevant for any stage of HRS image.

Hyperspectral and LIDAR data have fundamentally different characteristics. LIDAR data uses monochromatic NIR laser pulse that provides terrain characteristics. Conversely, HRS data used values of radiation reflected back from the surface at many wavelengths. Thus, a registration between HRS and LIDAR data has to be based upon an external format of integrative dataset. In this study, we choose to integrate the data based on extracted features from both HRS thematic map and LIDAR maps of the roofs and roads. Figure 4 showing a registration scheme.

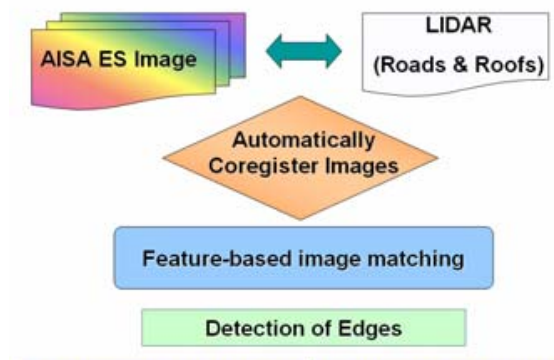

\begin{tabular}{|c|c|}
\hline $\begin{array}{c}\text { Specrta rules of decision } \\
\text { tree analysis }\end{array}$ & $\begin{array}{c}\text { Automatic increasing Tie } \\
\text { points based on edges }\end{array}$ \\
\hline
\end{tabular}

Figure 4. Automatic Registration Scheme

The image registration is mainly relied on edges and corners with respect to $4^{\text {th }}$ order polynomial function. 1. Images (Thematic HRS map and extracted LIDAR features map) were matched based on roads network of intersections and segmentations. 2. Roofs edges were selected as a fine tuning to registration process. The final steep focused on integrative spectral/spatial decision tree characterization.

TABLE 1: INTEGRATIVE DECISION TREE ANALYSIS

\begin{tabular}{||l|l|l|l||}
\hline CLASS/ & $\begin{array}{l}\text { SPECTRA } \\
\text { FEATURE }\end{array}$ & $\begin{array}{l}\text { SPATIAL/ } \\
\text { 3-D INFO }\end{array}$ & $\begin{array}{l}\text { INTEGRATED } \\
\text { INFO }\end{array}$ \\
\hline $\begin{array}{l}\text { Roads, } \\
\text { sidewalks, } \\
\text { parking lots }\end{array}$ & $\begin{array}{l}\text { Concrete } \\
\text { Asphalt }\end{array}$ & $\begin{array}{l}\text { Regular, } \\
\text { intersections } \\
\text { segmentations }\end{array}$ & $\begin{array}{l}\text { 1.Registration } \\
\text { matching feature } \\
\text { 2.Areas perimeter } \\
\text { calculation }\end{array}$ \\
\hline Roofs & $\begin{array}{l}\text { Tile and flat } \\
\text { roofs }\end{array}$ & $\begin{array}{l}\text { Reconstructed } \\
\text { features }\end{array}$ & $\begin{array}{l}\text { 1.Registration } \\
\text { matching feature } \\
\text { 2.Areas perimeter } \\
\text { calculation }\end{array}$ \\
& $\begin{array}{l}\text { Vegetation } \\
\text { Index } \\
\text { (NDVI) }\end{array}$ & Irregular points & $\begin{array}{l}\text { Average Height for } \\
\text { HDR class polygon }\end{array}$ \\
\hline Soil & $\begin{array}{l}\text { Soil Index } \\
\text { (SI) }\end{array}$ & Regular points & $\begin{array}{l}\text { 1.Slope/Aspect } \\
\text { calculation } \\
\text { 2.BRDF natural terrain }\end{array}$ \\
\hline Cars & $\begin{array}{l}\text { Metal and } \\
\text { Colour }\end{array}$ & $\begin{array}{l}\text { Dynamic } \\
\text { targets }\end{array}$ & $\begin{array}{l}\text { Points Height =0 } \\
\end{array}$ \\
\hline
\end{tabular}

The integrating process matched LIDAR extracted features to AISA ES thematic map in a non-earth coordinate system. Each pixel produced with a $Z$ (elevation) value without LIDAR projected $\mathrm{x}, \mathrm{y}$ coordinates. While roads, sidewalks, parking lots, vegetation and bare soils areas, required no spatial fitting or a fine tuning, the roofs mandatory an extra steps. The first step presented in figure 5 was a detection of roof edges. The roof edges matched a spatial distribution and configuration of AISA ES thematic map (classification image) with a two corner tie points (black markers). The registration algorithm chooses overlap LIDAR points within AISA ES class polygon by automatic routine. The edges were mapped by a combinative filter of high pass of $3 \times 3$ and median of $10 \times 10$ to straight features border.
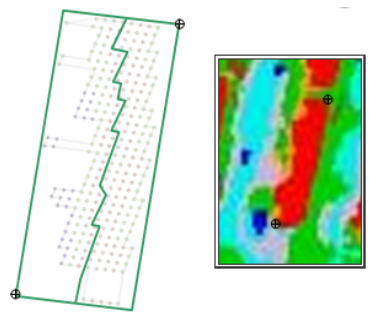

Figure 5. Detection of roof edges, on the right AISA ES thematic map on the left LIDAR reconstructed feature 
The next step was edges generalization and determination of central line. Figure 6 shows a final shape of the roof in the integrated dataset.

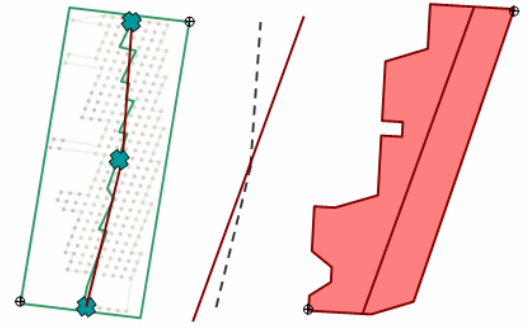

Figure 6. Determination of central line based on candidate points technique (blue marks). Final shape of the roof presented as red polygon

The final step was an automatic increasing of tie points based on edges and a roof section combination. To increase a number of tie points we collected first, all vertexes of a new integrated polygon and mapped a central line. Then, calculate gradient with equation (2) and linearly interpolate an elevation values (fig. 7).

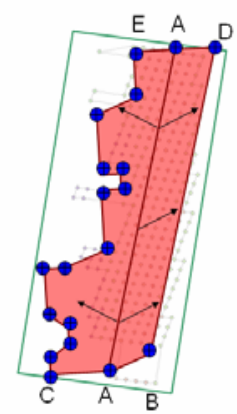

$$
\Delta=\mathrm{A} / \mathrm{D} \text { or } \mathrm{A} / \mathrm{B}
$$$$
\Delta=\mathrm{A} / \mathrm{E} \text { or } \mathrm{A} / \mathrm{C}
$$

Figure 7. An automatic increasing of tie points based on roof edges (blue point - vertex, character - selected vertexes)

The combination of a roofs features section managed by polygon to polygon relationship determent by topology roles and based on cluster/fuzzy tolerance with a determent distance range of one pixel (linear spectral unmixing) in which vertices are considered coincident.

\section{RESULTS}

Monitoring system as HRS gets quantitative information of urban environment and hazards. Those systems may help to base a rehabilitation strategy to assess the effectiveness of repairs and to determine the future repair cycle. Thus, it is highly important to have an application as a part of near real time monitoring system, which provides a quality of urban elements and materials. This research based on spectral characterization in reflective range of electro-magnetic radiation for creation of planning and engineering maps. The three dimensional mapping (Fig.8) and monitoring provides a powerful tool for planning and civil engineering.
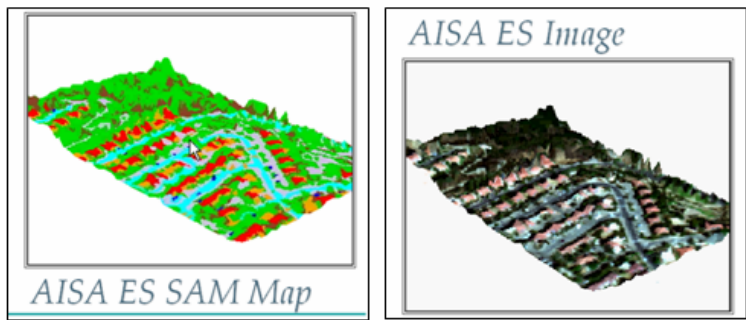

Figure 8. Final Product - Three dimensional HRS Image and Classification Map

\section{CONCLUSION}

The development of powerful analysis techniques for data fusion (HSR and LIDAR) can greatly contribute toward innovative mapping of urban environments estimate potential and further use to account for possible contamination in the urban environment.

The chemical composition of the urban materials can be estimated by spectral tools (Field spectrometer, Ground Hyperspectral Cameras, Airborne and Spaceborne Sensors) that together with LIDAR data may provide a new tool for decision makers: better surface properties map together with geometry in three-dimensional visualization. This can account not only for urban mapping, but also to the runoff chemical content, shade and shadow areas, shapes and forms of the urban elements. Doing so under temporal basis may increase the potential of the methodology developed here and may call for further work in this direction.

\section{REFERENCES}

1. Ridd M. K., 1995. Exploring V-I-S model for Urban ecosystem analysis through remote sensing, International Journal of Remote Sensing, 16, pp. 993-1000.

2. Roessner, S., Segl., K., Heiden, U., Munier, K. \& Kaufmann, H., 1998. Application of hyperspectral DAIS data for differentiation of urban surface in the city of Dresden, Germany. In: 1st EARSel Workshop on Imaging Spectroscopy, Zuerich, pp. 463-472.

3. Juan G., Martinez M., Velasco R., 2007, Hyperspectral Remote Sensing Application for Semi-Urban Areas Monitoring Urban Remote Sensing Joint Event, Volume, Issue , 11-13, pp. $1-5$.

4. Brook A., E. Ben-Dor, R. Richter, 2009, Spectral and Radiometric In-Flight Calibration Method for AISA ES Airborne Sensor, 6th EARSel Workshop, Tel-Aviv, Israel.

5. Kruse, F. A., Lefkoff, A. B., Boardman, J. B., Heidebrecht, K. B., Shapiro, A. T., Barloon, P. J., and Goetz, A. F. H., 1993, The Spectral Image Processing System (SIPS) - Interactive Visualization and Analysis of Imaging Spectrometer Data: Remote Sensing of Environment, Special issue on AVIRIS, v. 44, pp. $145-163$.

6. J. Gurgurewicz J.,2009, Mineralogy of Noctics Labyrinths on the basis of Omega/MEX AND PFS/MEX data, 40th Lunar and Planetary Science Conference, 3Institute of Geological Sciences PAS, Warsaw, Poland.

7. Goetz, A. F. H., Vane, G., Solomon, J. E., and Rock, B. N., 1985, Imaging spectrometry for earth remote sensing: Science, v. 228 , pp. $1147-1153$.

8. Noesset, E.,1996. Use of the weighted Kappa coefficient in classification error assessment of thematic maps. International Journal of Geographical Information Science, 10, 591-604

9. Sacks J., W. J. Welch, T. J. Mitchel, H. P. Wynn, 1989. "Design and Analysis of Computer Experiments", in Statistical Science, vol. 4 (4), pp. 409-435.

10. Cressie A. N. C., 1993. Statistics for Spatial Data, review, Wiley, New York

11. Masaharu, H., and Ohtsubo, K., 2002. A filtering method of airborne laser scanner data for complex terrain, The International Archives of Photogrammetry, Remote Sensing, and Spatial Information Sciences, Vol. XXXV, Part 3B, pp. 165-169, Graz, Austria.

12. Rottensteiner F., J. Trinder, S. Clode, K. Kubik, 2005, Automated Delineation of Roof Planes from LIDAR data, ISPRS WG III/3, III/4, V/3 Workshop "Laser scanning 2005", Enschede, the Netherlands. 